DOCTRINA

\title{
Nuevos panoramas en la organización administrativa del Estado: ¿Solución o complicación?
}

\author{
New prospects in the organization of the public administration: \\ Solution or complication?
}

\section{Manuel Patricio Vergara Rojas}

Universidad de Las Américas, Chile

\begin{abstract}
RESUMEN El presente trabajo analiza las diversas alternativas de reorganización de los servicios públicos ante las nuevas tareas del Estado, o bien, ante los problemas surgidos en la gestión de algunos de ellos, se evalúa su conveniencia y sugiriendo otras alternativas.
\end{abstract}

PALABRAS CLAVE Estado, administración, ministerios, servicios públicos, crítica, sugerencias.

ABSTRACT The present paper examines several alternatives in order to reorganize the public services to solve new tasks of the State, and in the case of problems created by the management of some, their convenience is evaluated and different alternatives are suggested.

KEYWORDS State, administration, ministry, public services, critics, suggestion.

\section{Introducción}

En las últimas dos décadas se han creado nuevos ministerios en el país, con el objetivo de mejorar la gestión y administración de los sectores a ellos asignados. Entre las nuevas secretarías de Estado están Desarrollo Social (Ley 20.530 de 2011), Energía (Decreto de Ley 2.224 de 1978, modificado por la Ley 20.776) Medio Ambiente (Ley 19.300 de 1994, modificada por la Ley 20.417); Deporte (Ley 20.686 de 2013); y de la Mujer y Equidad de Género (Ley 20.820 de 2015). También existen iniciativas para crear nuevas secretarías de Estado, como las de Culturas, de las Artes y del Patrimo- 
nio (Boletín 8.938-24 de 2013), ${ }^{1}$ en avanzado estado de tramitación, sin perjuicio de otras propuestas de las cuales se ha hablado en mayor o menor grado, tales como el Ministerio del Mar, ${ }^{2}$ Ministerio de Ciencia y Tecnología (Boletín 11.101-19) ${ }^{3}$ y Ministerio de los Pueblos Indígenas (Boletín 10.687-06)4, lo que ha causado comentarios en la prensa.

Junto con lo anterior, y producto de las severas fallas que afectan al aparato público en estos últimos años, ha logrado muchos partidarios la idea de establecer autonomías administrativas, de jerarquía constitucional incluso, como correctivo a dichas situaciones, comúnmente relacionadas con la designación de las autoridades superiores de servicios públicos, o bien con el ingreso a su personal idóneo en las materias de su competencia.

El objetivo del siguiente artículo es, en primer lugar, analizar los fundamentos de la creación y operación de los ministerios, para, en una segunda etapa, analizar la conveniencia de crear nuevas secretarías de Estado. En seguida, se tratará el caso de las autonomías en nuestro ordenamiento, con el fin de examinar la factibilidad y eficacia de crear nuevas entidades de este tipo en el cuadro orgánico de la Administración Pública. Una vez realizado dicho análisis, se efectuarán las propuestas para dar con la mejor solución para el fenómeno que abordamos.

\section{La proliferación de ministerios}

La actual versión de la Constitución Política de la República, entre sus artículos 33 a 37 bis, establece el estatuto constitucional de los ministros de Estado. Sin embargo, respecto de los ministerios sólo existe una referencia breve en dos disposiciones: en

1. Andrés Gómez, «Claudia Barattini, ministra de Cultura: «El nuevo proyecto de Ministerio de Cultura estará antes del 21 de mayo»", La Tercera, 24 de mayo de 2014, disponible en http://bit.ly/2kH5wbZ. Juan Ignacio Rodríguez Medina, «Entrevista a la ministra Claudia Barattini: Más integrado, menos colegiado: La propuesta para el nuevo Ministerio de Cultura y Patrimonio», El Mercurio, 30 de agosto de 2014, disponible en http://bit.ly/2kG345v. Magdalena Krebs, «Ministerio de Cultura», La Tercera, 31 de enero de 2017, disponible en http://bit.ly/2kH6QLZ.

2. Producto de la marea roja en Chiloé, algunos diputados hicieron la propuesta, que después mutó en una política sobre el tema. Una iniciativa más elaborada se encuentra en Urrutia y Weber (2016: 95 y ss.).

3. Rodrigo Iturriaga, Rodrigo Gutiérrez, Marcelo López-Lastra, Marcelo y Luis Larrondo. «Ministerio de Ciencia», La Tercera, 17 de mayo de 2016, disponible en http://bit.ly/2kG6aX6. Alberto Mordojovich, «Ministerio de Ciencia y Tecnología», La Tercera, 15 de enero de 2017, disponible en http://bit. ly/2kGoaAS. C. Espinoza y C. Yáñez, «Agencia de Investigación reemplazará a Conicyt», La Tercera, 17 de enero de 2017, disponible en http://bit.ly/2kHdDW5. José Miguel Jaque, «Mario Hamuy explica: Para qué necesitamos un Ministerio de Ciencia», La Tercera, 20 de enero de 2017, disponible en http://bit. ly/2kZoZRF.

4. Ocho años más tarde, por el Boletín 10.525-06, se presentó un primer proyecto el 19 de enero de 2016, que fue retirado presentándose el citado en el cuerpo de este texto. 
primer lugar, el inciso segundo del artículo 33, que señala «La ley determinará el número y organización de los ministerios, como también el orden de precedencia de los ministros titulares». Más adelante, en el artículo 38, bajo el epígrafe «Bases generales de la administración del Estado», en el comienzo del inciso primero señala: «Una ley orgánica constitucional determinará la organización básica de la Administración Pública». Nada más dice en torno a esta materia.

Por su parte, la Ley Orgánica Constitucional de Bases Generales de la Administración del Estado (LOC-BGAE), en su artículo 22, expresa textualmente en su inciso primero: «Los ministerios son los órganos superiores de colaboración del presidente de la República en las funciones de gobierno y administración de sus respectivos sectores, los cuales corresponden a los campos específicos de actividades en que deben ejercer dichas funciones». Dos expresiones nos interesan para nuestro análisis: «respectivos sectores», y «campos específicos de actividades». En primer lugar, el término «sector», según el Diccionario de la Lengua Española, significa en su segunda acepción: «Cada una de las partes de una colectividad, grupo o conjunto que tiene caracteres peculiares o diferenciados». El sector sería, entonces, una parte o área de una colectividad, en este caso del país, que posee ciertas características que lo distinguiría de otros y para los que, por su importancia, se crean los ministerios con el objeto de ejercer la función de gobierno y administración. En segundo lugar, está la expresión «campos específicos», que caracteriza al «respectivo sector». La palabra "campo», según el diccionario antes citado, dice en la décima acepción: «Ámbito real o imaginario propio de una actividad o de un conocimiento». Por su parte, la palabra «específico», según la citada obra es, en la segunda acepción, sinónimo de preciso o determinado. En suma, los ministerios, al ser creados por ley, se desempeñan en un área de la comunidad referida a una actividad determinada, y es en esa porción característica y precisa de actividad, compuesta por varios campos o subsectores determinados, donde se desempeña en el gobierno y la administración. En consecuencia, los ministerios deben tener asignados esa área de interés en la sociedad para cumplir con su misión en diversos y delimitados campos.

La siguiente pregunta es: ¿ cómo se determinan esas áreas de la sociedad en que se establecerán los ministerios? La respuesta es de tipo político y está sometida a la discreción o criterio de la autoridad de turno. Un ejemplo puede servir de guía: en un país donde la actividad minera no sea de vital importancia, puede estar comprendida en el Ministerio de Economía, a diferencia del caso chileno. En cambio, el turismo, como principal fuente de ingresos en algunos países, tiene un ministerio propio. Un caso particular es Egipto que, por razones obvias, tiene un Ministerio de Antigüedades. Dependerá, entonces, de diversos factores establecer el área o sector de los diferentes ministerios para determinar su número total.

El problema consiste en establecer criterios políticos estables y objetivos para determinar la creación o fusión de las diversas secretarías de Estado, con el propósito de 
no fragmentar excesivamente la actividad gubernamental, so pretexto de abordar de mejor forma ciertas áreas que se consideren importantes.

En nuestro país se optó por mejorar la gestión del sector o subsector respectivo, el cual se ha considerado con una trascendencia que previamente no poseía, a través de crear un ministerio propio, o bien, elevar a dicha categoría a entidades ya existentes. Pese a ser ésta la alternativa escogida, la raíz del problema que aqueja a nuestro país no parece provenir desde esa óptica, sino más bien, desde el punto de vista operativo.

La LOC-BGAE, en el inciso segundo de su artículo 22, dispone que los ministerios,

para tales efectos, deberán proponer y evaluar las políticas y planes correspondientes, estudiar y proponer las normas aplicables a los sectores a su cargo, velar por el cumplimiento de las normas dictadas, asignar recursos y fiscalizar las actividades del respectivo sector.

Entonces, este nivel administrativo tiene una labor de establecer las grandes guías del sector, esto es, fijar políticas, planificar acciones, generación y cumplimiento de normas, asignación y fiscalización del uso de los recursos respectivos. Remata el inciso tercero del mismo artículo efectuando la distinción con los servicios públicos al señalar que «en circunstancias excepcionales, la ley podrá encomendar alguna de las funciones señaladas en el inciso anterior a los servicios públicos. Asimismo, en los casos calificados que determine la ley, un ministerio podrá actuar como órgano administrativo de ejecución». Es decir, en suma, el ministerio es un órgano administrativo de tipo superior, encargado de la estrategia, a contrario sensu de lo señalado en el inciso segundo.

Confrontada esta normativa, concluimos que, en la actualidad, las estructuras ministeriales vigentes no cumplen con su función a cabalidad, por lo cual se adopta la decisión política de crear una nueva secretaría de Estado. En consecuencia, se establece un nuevo ministerio para generar toda planificación, en sentido amplio, con el objeto de posteriormente efectuar su aplicación mediante los órganos de ejecución que lo integran.

Siendo ésta la solución, ¿se justifica la creación de más ministerios? ¿Crear más ministerios no será contraproducente, al generar más burocracia de difícil manejo? ¿Es mejor hacer cambios internos en las secretarías de Estado? La conclusión la mencionamos al principio de este apartado: es una decisión política. El incremento del aparato estatal puede ser contraproducente, como sucedió en Brasil, donde tras la suspensión de Dilma Rousseff como presidenta, producto de la grave crisis económica, una de las primeras medidas del gobierno interino fue la reestructuración del Estado, al reducir el número de ministerios desde 31 hasta 23 , fusionando, por ejemplo, Educación con Cultura, entre otras medidas.

En Chile, un claro ejemplo de este dilema es el caso del Ministerio de Educación con los proyectos de los ministerios de Cultura y de Ciencia y Tecnología. Es de pú- 
blico conocimiento que el sector educación está sometido a una fuerte presión por diversos motivos, lo que ha llevado a un proceso de reformas necesarias pero polémicas. También es sabido que muchos servicios y entidades dependientes relacionadas con la cultura han sido dejados de lado por bastante tiempo, debido a las diversas exigencias en materia educacional, manejándose el aspecto cultural en el nivel formativo primario, secundario y universitario. Algo parecido sucede con la ciencia y la tecnología, un sector que por razones históricas ha padecido postergación (recursos, desinterés, etcétera). Si bien es cierto que hay una relación estrecha con la parte productiva (empresas), también existe un vínculo innegable con las universidades (ellas enseñan a los futuros profesionales y científicos) y centros de investigación, muchas veces anexos o relacionados a ellas.

El fuerte impulso que se pretende otorgar en el ámbito cultural y científico justificaría la creación de entidades ministeriales. La pregunta obvia sería: ¿es necesario crear un ministerio o es mejor una estructura interna dentro del Ministerio de Educación, quizás dependiente de un subsector o bien constituyendo los específicos para educación, de cultura y de ciencias?

Cualquiera sea la solución, el problema mayor no sólo será la justificación de un nuevo ministerio, sino cómo se relacionará éste y sus órganos ejecutivos entre ellos y con las demás entidades de la Administración. ¿Estará su competencia bien descrita? ¿Tienen sus facultades o atribuciones bien delimitadas? ¿Hay mecanismos para coordinar la actividad y resolver los problemas que se susciten? ¿Existen los recursos necesarios para cumplir con la función establecida en la norma? Respondidas estas interrogantes, puede llegarse al caso que, incluso, no sea necesaria la creación de un nuevo ministerio, sino el reordenamiento y redistribución de las competencias dentro de la estructura ministerial para cumplir con los objetivos establecidos. En consecuencia, ¿no será mejor reconfigurar las subsecretarías como nivel administrativo desde meros órganos de gestión interna a unas entidades que tengan algunas de las facultades generales que poseen los ministerios en la actualidad?

En este sentido, Enrique Silva Cimma, al hablar sobre la reforma a la Administración Pública, propuso entre otras medidas de carácter más amplio, fusionar algunos ministerios y crear otros sin cartera, establecer el cargo de viceministro al margen de los subsecretarios, disminuir el número de ministerios y agruparlos en áreas (gobierno, regulatoria económica, infraestructura y desarrollo urbano, y social) (Silva Cimma, 2008: 112-113). ${ }^{5}$

Esta es una solución aplicada en otros países, como España, en cuya Ley 50/1997 del Gobierno y en la Ley 6/1997 de Organización y Funcionamiento de la Adminis-

5. En 2009, el denominado Consorcio para la Reforma del Estado propuso, entre otras medidas, restructurar las subsecretarías como entes administrativos y no políticos, y trasladar esta labor a los jefes de gabinetes y asesores. 
tración General del Estado, se establecen los cargos de ministro, secretario de Estado y subsecretario. El primero a cargo del departamento (ministerio); el segundo como directores y coordinadores de direcciones generales (sector de actividad específica de un departamento); y el tercero, como un funcionario orientado a una labor interna (Ley de España 50/1997, 1997, artículos 4 y 7; Ley de España 6/1997, 1997, artículos 8, 9, 12, 14 y 15$)$.

Como se observa, existen fórmulas alternativas a la creación de nuevos ministerios, tal como señala Boloña Kelly, con la agrupación de algunos existentes, conjuntamente con una reordenación interna de la respectiva secretaría de Estado (Boloña, 2008: 378-379). Si se llega a un punto muerto, será necesario ajustar la estructura general de la Administración del Estado.

\section{La marea autonomista}

\section{Situación general}

Los casos del Instituto Nacional de Estadísticas por el fallido censo del año 2012 y del Servicio de Impuestos Internos debido a la polémica por el financiamiento político irregular y su persecución en tribunales, ha creado la sensación en la opinión pública y ciertos círculos políticos de que la solución a estos problemas sería otorgarles a ambas entidades jerarquía constitucional, o bien, hacerlas autónomas, como es el caso del Banco Central, por ejemplo.

Debemos efectuar distinciones previas antes de entrar al fondo. Según expuse anteriormente (Vergara, 2010: 21 y ss.), debemos distinguir entre los conceptos «órgano» y «organismo». Por el primero, entiendo aquellas entidades integrantes de la Administración del Estado que están sometidas al vínculo de dependencia o supervigilancia, si son centralizadas o descentralizadas, respectivamente. Por organismo, comprendo aquellas entidades autónomas desplazadas del esquema anteriormente señalado.

Las entidades centralizadas tienen personalidad jurídica y patrimonio fiscal y se sujetan a la dependencia del presidente de la República a través del respectivo ministerio. En cambio, las entidades descentralizadas tienen personalidad jurídica y patrimonio propio distintos del fiscal y están sujetos a la supervigilancia del presidente de la República a través del ministerio respectivo, pudiendo ser funcional o territorialmente descentralizadas.

Otro tanto sucede con las autonomías, las que se caracterizan por poseer una personalidad jurídica distinta del fisco, patrimonio propio diferente del fiscal y con autonomía en su manejo, consagración y regulación básica en la Constitución y en una ley orgánica constitucional, procedimiento de designación mixta de sus autoridades superiores, designación de su plana mayor por parte de su autoridad superior y, por 
último, potestad reglamentaria interna propia. Esto no obsta que se relacionen con el Gobierno a través de un ministerio determinado, pero dicho vínculo no cae en las categorías de dependencia o supervigilancia.

Debemos recordar que las denominadas «autonomías constitucionales», sean administrativas o jurisdiccionales, nacieron para extraer ciertas funciones que se estimaba no debían estar en un nivel de actividad general, sino que, por su importancia, convenía separarlas de la actividad general de la cual se desprenden. Rolando Pantoja señala en este punto:

Los órganos y organismos autónomos son organizaciones jurisdiccionales, técnicas, asesoras o de carácter social que dentro del Código Político no dependen ni se relacionan con el Gobierno, el Congreso Nacional o el Poder Judicial, encontrándose sometidos directamente a la Constitución Política de la República y a una preceptiva legal que por mandato constitucional regula su generación y funcionamiento (Pantoja, 1998: 290).

Precisando en lo administrativo, el mismo autor señala que se pretende «liberar a estas organizaciones de la sujeción jerárquica del Supremo Administrador del Estado o de su supervigilancia o tutela, para permitirles, desde otra óptica, operar dentro de una gestión que les facilitara la materialización de las correspondientes políticas públicas». Las denomina como «acentralizadas» (Pantoja, 2010: 22-23).

Por su parte, Gabriel Celis señala, respecto de las autonomías que están compuestas por aquellos órganos previstos y regulados directamente, ya sea por la Carta Fundamental o la ley, «que desarrollan sus funciones al margen del principio de jerarquía del poder central y tampoco actúan bajo un sistema de tutela o supervigilancia del presidente de la República» (Celis, 2016: 92-93).

También Silva Cimma señala:

el hecho de que un organismo sea autónomo no significa que tenga un poder de autorregulación equivalente al legislador [...] El hecho que la Constitución declare a un organismo autónomo, significa entonces que no queda sometido a las órdenes de otros órganos que no sean el legislador (Silva Cimma, 2008: 218).

Siguiendo y actualizando las ideas de Pantoja (Pantoja, 1998: 290 y ss.), encontramos en la Constitución: al Tribunal Constitucional (artículo 92) y el Tribunal Calificador de Elecciones y sus derivados como Tribunales Electorales Regionales (artículos 95 y 96), los que por su función no están integrados en el Poder Judicial. Por su parte, la Contraloría General de la República (artículo 98), el Banco Central de Chile (artículo 108) y el Servicio Electoral (artículo 94 bis), por su trascendencia, también son extraídos de la administración y llevados a una jerarquía superior. El caso del Ministerio Público (artículo 83), mixto entre jurisdiccional y administrativo, es otro que justificó su exclusión de la administración general, por su especial función. En último 
lugar encontramos los Gobiernos Regionales (artículo 111) y las municipalidades (artículo 118). Observados con detención, ellos se refieren a situaciones muy especiales: jurisdicción constitucional, administración y justicia electoral, administración pasiva (fiscalización), regulación de aspectos monetarios, intervención en el proceso penal en representación del Estado y, por último, gobierno interior del Estado.

Concentrándonos en las autonomías administrativas, en primer lugar, debemos referirnos a la Contraloría General de la República. Si bien no posee una personalidad jurídica y patrimonio diferente del fiscal, tiene todos los demás atributos, con la salvedad que su ley orgánica constitucional está contenida en el Decreto 2.421 de 1964, texto refundido, coordinado y sistematizado de la Ley 10.336, sobre su organización y atribuciones (LOA-CGR), de jerarquía orgánico-constitucional según el artículo cuarto transitorio de la Constitución. Su jefe superior es designado por el presidente de la República con acuerdo del Senado (artículo 3) y no es removible salvo juicio político; su estructura interna puede ser modificada por el Contralor (artículo 2, inciso quinto), los empleados de la Contraloría son de exclusiva confianza de su jefe superior (artículo 3), y su personal se rige por el Estatuto Administrativo, según se desprende de sus normas respectivas (artículos 44 y siguientes).

Con respecto al Banco Central de Chile, posee los requisitos establecidos, con la salvedad que en la Constitución no se habla expresamente de la personalidad propia, lo que sí hace el artículo 1 Ley Orgánica Constitucional 18.840 (LOC-BCCH). Tiene una norma distintiva: el artículo 90 señala de forma sibilina que «no se aplicarán al Banco [...] ni la Ley 18.575", yendo contra texto expreso de una norma que, aunque del mismo rango normativo, por contenido es de superior aplicación. Sus consejeros son elegidos por el presidente de la República con acuerdo del Senado (artículo 7), y son removibles, en el caso del presidente del Consejo, por el presidente de la República con el consentimiento del Senado y a solicitud de tres miembros del Consejo (artículo 16), y en el caso de los demás, por el presidente de la República con el acuerdo del Senado (artículo 17). Por otra parte, el número 3 del artículo 18 señala que el Consejo determinará el reglamento del personal del Banco, la estructura administrativa de la institución, la o las plantas de personal y fijará las remuneraciones y cualquier otro estipendio o beneficio del personal del Banco. Según el artículo 81, su personal se rige por las normas de la ley y supletoriamente por las normas del Código del Trabajo y del sector privado, y no por las del Estatuto Administrativo, como sería lógico.

Por último, el Servicio Electoral, según su nueva legislación en la Ley Orgánica Constitucional 18.556 sobre Sistema de Inscripciones Electorales y Servicio Electoral (LOC-SIESE), cumple con todas las características que hemos mencionado (artículo 57). Su órgano superior es el Consejo Directivo, cuyos miembros son designados por el presidente de la República con acuerdo del Senado, y son removibles sólo por causales establecidas por dictamen de la Corte Suprema a requerimiento del presidente de la República, o de un tercio de los miembros en ejercicio de la Cámara de 
Diputados (artículo 94 bis de la Constitución Política en relación con artículos 62 y siguientes de LOC-SIESE). Su personal se rige por las normas estatutarias, según lo dispone de forma poco clara el artículo 71. Su ley de planta es la 18.583, también de rango orgánico constitucional, que regula expresamente el punto.

Hemos descartado en nuestro presente análisis a los Gobiernos Regionales y municipios por su particular labor de tipo territorial, al Ministerio Público por su funcionamiento relacionado con la jurisdicción, y a las Fuerzas Armadas y de Orden y Seguridad por su peculiar misión y régimen de actividad.

En los tres casos mencionados encontramos entidades de regulación (Banco Central), fiscalización y control (Contraloría) y de administración electoral (Servicio Electoral). Por su trascendencia se ha estimado indispensable otorgarles un estatuto especial. Sin embargo, existen otros casos a nivel constitucional que llegan a soluciones similares y que merecen ser analizados.

\section{Nuevas figuras creadas en el sistema}

\section{Consejo Nacional de Televisión}

En primer lugar, hallamos lo que acontece con el Consejo Nacional de Televisión (CNTV), calificado en el inciso sexto del número 12 del artículo 19 de la Constitución, como «entidad autónoma y con personalidad jurídica» y regulado por una ley de quórum calificado. Su situación cambió en los últimos años. Según la Ley 18.838, que lo crea, en su artículo 1 original señalaba que era «un servicio público autónomo, funcionalmente descentralizado, dotado de personalidad jurídica y patrimonio propio, que se relacionará con el presidente de la República por intermedio del Ministerio de Transportes y Telecomunicaciones» (Ley 18.838 de 1989; el destacado es nuestro). De acuerdo a su última versión, producto de la reforma de la Ley 20.750, se le caracteriza como institución autónoma de rango constitucional, además de «dotado de personalidad jurídica y patrimonio propio, que se relacionará con el presidente de la República por intermedio del Ministerio Secretaría General de Gobierno». Por último, el inciso segundo establece que «no le serán aplicables las normas generales o especiales, dictadas o que se dicten para regular la Administración del Estado, tanto centralizadas como descentralizadas».

La norma que lo regula no es orgánica constitucional, sino de quórum calificado. También, se le atribuye el poseer jerarquía constitucional, lo cual no es totalmente efectivo a nuestro juicio, debido a que sólo existe una mención menor no comparable a la establecida para los organismos ya mencionados anteriormente. En efecto, éstos tienen sus propios capítulos con descripción detallada de su naturaleza jurídica, funciones, integración y remisión a normativa de rango orgánico constitucional. Nada de ello posee el CNTV en la carta magna, por lo cual atribuirle el carácter autónomo, 
en los términos que hemos descrito, no procede. En todo caso, puede contribuir a dicha idea cuando se señala, además, que no se le aplica la norma de las entidades centralizadas o descentralizadas. Por último, se observa en la descripción original de la entidad, una confusión muy común en algunas leyes: mencionar un órgano como autónomo, para después describirlo como funcionalmente descentralizado.

En un análisis detallado, los once miembros de su jefatura superior, salvo uno de libre designación presidencial, son elegidos de forma mixta con la participación del Senado, aplicándoseles las normas de probidad y declaración de intereses y patrimonio (artículo 2). En cuanto a su término de funciones, establece causales precisas para ello, dentro de las cuales las tres últimas implican la participación de la Corte Suprema, y la iniciativa del presidente de la República, la Cámara de Diputados o diez de sus miembros, el mismo consejo o, en un solo caso, de cualquier persona (artículo 10). En cuanto a su personal, está sometido a las normas del Estatuto Administrativo (artículo 41).

Encontramos, en suma, una institución que tiene pretensiones de autonomía constitucional, pero que no cumple con todos los estándares que hemos fijado, pues es un híbrido entre la descentralización funcional y la autonomía.

\section{Consejo para la Transparencia}

Un segundo caso de autonomía, no mencionada expresamente en la Constitución (inciso segundo del artículo 8), es el llamado Consejo para la Transparencia, establecido en la Ley 20.285, norma de jerarquía quórum calificado, según la citada disposición constitucional (Ley 20.285 de 2008). El artículo 31 de la Ley 20.285 (artículo primero), conceptúa a la entidad como «corporación autónoma de derecho público, con personalidad jurídica y patrimonio propio». Más adelante, el inciso tercero señala: «Los decretos supremos que se refieran al Consejo, en que no aparezca una vinculación con ministerio determinado, serán expedidos a través del Ministerio Secretaría General de la Presidencia».

Como observamos, se habla de autonomía sin describir el vínculo como supervigilancia o tutela, por lo cual no estaríamos frente a una descentralización funcional. Tampoco establece un ministerio específico para vincular a la entidad con el presidente de la República, haciendo uso de la extraña fórmula de recurrir a decretos de diversos ministerios para formalizar este vínculo. Utiliza, además, el término «corporación», de uso eventual en derecho público.

El método de designación de sus cuatro consejeros se efectúa a través de una propuesta presidencial con el acuerdo del Senado (artículo 36), fórmula utilizada en las entidades autónomas constitucionales. Extraño para un servicio público, como el caso anterior, es el procedimiento de su remoción, que opera invocando ciertas causales con la participación de la Corte Suprema, previo requerimiento del presidente 
de la República, la Cámara de Diputados por acuerdo de simple mayoría o solicitud de diez diputados (artículo 38).

La generación de sus estatutos la hacen los miembros del Consejo, pero debe ser propuesto al presidente de la República y su vigencia se efectúa a través de un decreto expedido por el Ministerio Secretaría General de la Presidencia (artículo 41). Esto es totalmente extraño para una entidad denominada «autónoma».

En el punto donde más escapa su regulación es el régimen de personal. La regla es el Código del Trabajo, pero se le aplican las normas sobre la ley de probidad, de prevención de conflictos de intereses y las pertinentes de la LOC-BGAE. A quienes ejerzan funciones directivas se les aplica las normas de la ley sobre Alta Dirección Pública y, cerrando este extraño sistema, es fiscalizado por la Contraloría General de la República respecto de su personal y el juzgamiento de cuentas, si bien sus resoluciones no se someten a la toma de razón (artículo 43). Este es un caso aún más excéntrico que el anterior, debido a que rompe con reglas de común utilización en el estatuto funcionario de sus autoridades superiores y personal, además de su naturaleza jurídica administrativa.

También, el estatuto de funcionamiento del Consejo para la Transparencia, el Decreto 20 , de 23 de mayo de 2009 , precisa en su artículo 22 que un reglamento establecerá las unidades funcionales para el cumplimento de su cometido.

En suma, tanto para el Consejo Nacional de Televisión como el Consejo para la Transparencia, factores de tipo práctico han justificado al legislador no ajustarse a las tipologías conocidas. En ambos casos se les trata de autonomía, aunque según lo descrito no se parecen a las establecidas en la Constitución, sino más bien una versión de avanzada o moderna respecto de la descentralización funcional y, a nuestro juicio, de rango legal tal como lo clasifica Celis (Celis, 2016: 92-93). Sin embargo, la idea de autonomía legal no parece estar del todo asentada, como señala Becerra, quien expresa, respecto de estos órganos como parte de la administración del Estado,

convirtiéndose en órganos descentralizados, que, por tanto, gozan de personalidad jurídica propia y, como consecuencia de ello, con un patrimonio propio, teniendo cierto grado de independencia funcional y orgánica, pero que no pueden desligarse del vínculo de tutela que los une con el poder central, pues forman parte del mismo (Becerra, 2011: 331).

Dejamos de lado en este análisis el caso de las universidades del Estado, que muchas veces no son consideradas dentro de las autonomías (en este caso de jerarquía legal) (Celis, 2016: 93-94); ni consideramos a los centros de formación técnica estatales de reciente creación por la Ley 20.910, que en cada caso son descritas como entidades con "persona jurídica de derecho público autónoma, funcionalmente descentralizada, con personalidad jurídica y patrimonio propio» (Ley 20.910 de 2016). 
Las categorías van evolucionando debido a las finalidades de las instituciones y, es preferible que éstas funcionen, en vez de ajustarse a una tipología que no cumpla cabalmente con los objetivos perseguidos. Queda, entonces, establecer si estas nuevas categorizaciones provocarán un efecto distorsionador en el conjunto.

\section{El caso de las superintendencias}

Un caso digno de investigación está constituido por las superintendencias. En los artículos 2 y 3 del Decreto Ley 3.551, se caracteriza la noción de institución fiscalizadora. En efecto, el artículo 2 señala:

Serán instituciones autónomas, con personalidad jurídica, de duración indefinida, y se relacionarán con el Ejecutivo a través de los ministerios de los cuales dependen y se relacionan en la actividad. Estas instituciones serán denominadas para todos los efectos legales, como «instituciones fiscalizadoras».

El artículo 3 dice en su totalidad:

El jefe superior de cada una de las instituciones fiscalizadoras, será de la exclusiva confianza del presidente de la República y se mantendrá en su empleo mientras cuente con ella. Dichos jefes superiores gozarán de la más amplia libertad para el nombramiento, promoción y remoción del personal de la respectiva institución, con entera independencia de toda otra autoridad. Para estos efectos, todo el personal que de ellos depende es de su exclusiva confianza (Decreto Ley 3.551 de 1981).

Estas disposiciones son importantes, porque muchas normas que regulan las superintendencias se remiten a ella de forma directa o indirecta.

Sin embargo, como acertadamente precisa Camacho, las superintendencias son un tipo de entidad fiscalizadora, existiendo otras como la Dirección del Trabajo y el Servicio de Impuestos Internos, que abordaremos más adelante. Aquellas entidades se distinguen de las últimas porque se fiscaliza de manera especializada «servicios que, aunque gestionados por agentes privados, se reconocen por el legislador como de interés público en áreas como la electricidad, servicios sanitarios, salud, seguridad social, etcétera» (Camacho, 2010: 150 y ss.).

A continuación, efectuaremos el análisis particular de las superintendencias existentes y de una de eventual existencia.

\section{Bancos}

En esta entidad se establece su carácter de institución autónoma, con personalidad jurídica, de duración indefinida y que se relaciona con el Gobierno a través del Ministerio de Hacienda. Señala explícitamente que no pertenece a la Administración Orgánica del Estado, a pesar de su carácter de institución de derecho público. Por 
último, establece que no se le aplican las normas generales o especiales relativas al sector público y que sus integrantes se rigen por normas del sector privado, sin perjuicio de lo establecido en el artículo 5, que establece que el personal es designado por el superintendente y que serán considerados como de exclusiva confianza de dicha autoridad (artículo 1). Según el artículo 3, el superintendente es designado por el presidente de la República. Los funcionarios se rigen por la ley, el Estatuto de Personal y, supletoriamente, por el Estatuto Administrativo (Decreto con Fuerza de Ley 3, 1997).

En este caso, debemos tener presente que la norma original proviene del Decreto Ley 1.097 (1975), en una época en que aún no se había dictado la LOC-BGAE y, seguramente, respondía a la intención del gobierno de turno de destrabar el funcionamiento de la Administración del Estado. Esto explica que señale no pertenecer a la Administración Orgánica del Estado, entendemos administración centralizada. Lo mismo puede decirse respecto de no establecer las normas del Estatuto Administrativo como de general aplicación, sino que supletorias a las establecidas en la ley y estatuto, esto es, el Código del Trabajo. Con respecto al superintendente, se entiende que es de exclusiva confianza del presidente. Es evidente que la Superintendencia pertenece a la Administración del Estado, pero no parece ser una entidad descentralizada, sino una autonomía de jerarquía legal y no constitucional.

\section{Valores y Seguros}

Debemos hacer aquí un doble análisis. Primero, según la antigua normativa, se le caracteriza como organismo autónomo, con personalidad jurídica y patrimonio propio, que se relaciona con el presidente a través del Ministerio de Hacienda (artículo 1). Se estableció que la Superintendencia y su personal no se rigen por las normas generales o especiales dictadas o que se dicten para la Administración del Estado, tanto centralizada como descentralizada, salvo el Decreto Ley 1.236, sobre Administración Financiera del Estado (artículo 2). El superintendente, según el artículo 7, es funcionario de exclusiva confianza del presidente y posee la facultad, según el artículo 8, de establecer la organización interna de la entidad, con sujeción a la planta y dotación máxima. En relación con el personal, el artículo 22 señala que el superintendente designará a todo el personal de la entidad. La norma que regula a los funcionarios será un estatuto de personal dictado por el presidente de la República y cuya norma supletoria será el Código del Trabajo y leyes complementarias. Sin perjuicio de lo anterior, el superintendente y su personal son considerados funcionarios públicos para los efectos de la responsabilidad penal, desahucio y legislación previsional (Decreto Ley 3.538 de 1980).

Como observamos, es otra autonomía de jerarquía legal, con su jefatura superior de exclusiva confianza del presidente de la República, pudiendo el superintendente designar libremente a todos sus funcionarios. Se rige por una norma especial y con 
el Código del Trabajo de forma supletoria. Volvemos a efectuar el mismo comentario previo: estamos frente a una norma anterior a la LOC-BGAE, lo que justifica la opción tomada en torno a su estructuración.

Segundo, y sin perjuicio de lo anterior, podemos confrontar esta regulación con la surgida a propósito de su reciente reforma por la Ley 21.00o (2017). Esta nueva normativa transforma a la Superintendencia en la «Comisión para el Mercado Financiero», explicitando su misión en el inciso segundo del artículo 1. En general, repite en el nuevo artículo 3 los contenidos del anterior artículo 2.

En cuanto a su naturaleza, el nuevo artículo 1 se decanta por caracterizar a la nueva entidad como «servicio público descentralizado, de carácter técnico, dotado de personalidad jurídica y patrimonio propio, que se relacionará con el presidente de la República a través del Ministerio de Hacienda», actualizando la naturaleza jurídica de la entidad a las categorías vigentes desde 1986 en la LOC-BGAE, con lo que elimina la expresión «autónomo», que induce a error.

Respecto de la normativa aplicable a la comisión y su personal, reconoce expresamente la aplicación de tres normas: la LOC-BGAE, la Ley 19.880 sobre Procedimiento Administrativo y la 20.880 sobre Probidad en la Función Pública y Prevención de Conflictos de Intereses (artículo 2). Esto contrasta notoriamente con lo dispuesto en el antiguo artículo 2, que no hacía aplicable a la Superintendencia y su personal «las normas generales o especiales dictadas o que se dicten para regular la administración del Estado, tanto centralizada como descentralizada, salvo lo dispuesto en el Decreto Ley 1.236» (Administración Financiera del Estado). Esto también es notable, ya que expresamente lo somete a toda la normativa del sector público, lo que no ocurría antes. Lo anterior se debe también al hecho de que el decreto ley original se dictó en una época cuando las normas señaladas no existían y a que, como vimos, en dicha época se buscaba modernizar la normativa de la Administración Pública. Hemos de señalar que la aplicación del Decreto Ley 1.236 quedó en el inciso segundo del artículo 6 nuevo.

También debe tenerse presente que el número 7 del artículo 21 señala que es una facultad del presidente de la Comisión «establecer oficinas regionales cuando el buen funcionamiento de la Comisión así lo exija», lo cual le otorga mucha independencia en el manejo de la entidad. Sin embargo, desapareció la norma que hablaba expresamente de la facultad del superintendente de establecer la organización interna de la entidad con sujeción a la planta y dotación máxima. Una norma que toma su lugar es el inciso segundo del artículo 8, en concordancia con el número 6 del artículo 20, donde se refiere a la facultad de la comisión de establecer «una normativa interna de funcionamiento, la que determinará los aspectos básicos para su funcionamiento, y para el cumplimiento de las obligaciones encomendadas por esta ley y contendrá, en general, todas aquellas disposiciones que le permitan una gestión eficiente». Sin embargo, no es tan clara como la antes señalada. 
En cuanto a sus miembros, deja de existir una autoridad unipersonal, sustituyéndose por una jefatura superior colegiada denominada «Comisión de Mercado Financiero", lo que es congruente con lo dispuesto en el inciso tercero del artículo 31 de la LOC-BGAE. Según el artículo 9, esta entidad está compuesta por cinco miembros: uno, designado por el presidente de la República, que será el presidente de la Comisión, tendrá la calidad de jefe superior del servicio y gozará de las facultades y atribuciones pertinentes (artículo 21); los cuatro restantes serán elegidos por el presidente de la República con acuerdo de los cuatro séptimos del Senado. Todos ellos deberán tener reconocido prestigio profesional o académico en el área del sistema financiero. Los designados en conjunto con el Senado durarán seis años en su cargo, renovándose por parcialidades cada tres años. Su remoción se establece en el artículo 14: expiración del plazo, renuncia, incapacidad física o síquica, sobrevivencia de causal de inhabilidad o incompatibilidad e incumplimiento grave de funciones y deberes. Respecto de la última causal, si los miembros fueran los de designación presidencial con acuerdo del Senado, son acusados ante la Corte Suprema; en el caso del designado por el presidente de la República, sólo compete a éste removerlo, operando como de su exclusiva confianza.

En esta nueva regulación varias cosas llaman la atención. En primer lugar, la profusión en el uso de entidades superiores colegiadas, siendo una decisión del legislador. También, es llamativa la participación del Senado en la designación de ciertos comisionados como, asimismo, la intervención de la Corte Suprema en la remoción de los mismos. Creemos que es una forma de salvar los problemas generados por el deficiente sistema de selección que ha empezado a corregirse con la Alta Dirección Pública. También es llamativa la intención de hacer designar al presidente de la Comisión al inicio del respectivo período presidencial, lo que creemos es una especie de equilibrio, en el sentido de que, si bien hay una comisión de tipo técnico, no deja de ser un servicio público dentro de la administración que encabeza el presidente de la República (artículo 9 número 1). En ese punto lo acerca a los establecido en los artículos 7 y 8 de la LOC-BCCH, pero ajustándolo al período presidencial respectivo.

Por último, respecto del personal el artículo 26, señala que éste se regirá por un estatuto de personal establecido especialmente al efecto. En lo no previsto por éste operará como norma supletoria el Código del Trabajo. Cierra el sistema señalando que el presidente de la Comisión podrá nombrar y remover con entera independencia al personal, salvo las excepciones legales. En esto no innovó la nueva normativa.

\section{Seguridad social}

Según esta norma, modificada por la Ley 20.691, la entidad es un servicio público funcionalmente descentralizado, con personalidad jurídica y patrimonio propio, que se relaciona con el presidente de la República a través del Ministerio del Trabajo y Pre- 
visión Social, por intermedio de la Subsecretaria de Previsión Social. Se le caracteriza como entidad fiscalizadora según el Decreto Ley 3.551, y se le aplica el sistema de la Alta Dirección Pública (artículo 1). El superintendente es nombrado por el presidente de la República, según las normas del título 4 de la ley de Alta Dirección Pública (artículo 4); el personal se rige por las normas del Estatuto Administrativo (artículo 7); y a pesar de que se establece una estructura básica y ciertos límites, puede establecer la organización interna y determinar atribuciones y funciones, con sujeción a la planta y dotación máxima de personal (artículo 8) (Ley 16.395 de 1966).

Esta norma, si bien es de antigua dictación, posee una versión modernizada como hemos mencionado, que derechamente cumple con los parámetros establecidos en la LOC-BGAE, al calificarlo como «servicio público funcionalmente descentralizado, con personalidad jurídica y patrimonio propio, que se relaciona con el presidente de la República» a través de un ministerio específico. El personal se rige por el Estatuto Administrativo y su jefe superior es designado a través del sistema de Alta Dirección Pública, según el título 4 de la Ley 19.882, que en el artículo quincuagésimo octavo señala en cuanto a su remoción, que será considerado de exclusiva confianza del presidente de la República.

\section{Electricidad y combustible}

Está configurada como un servicio público funcionalmente descentralizado, que se relaciona con el Gobierno a través del Ministerio de Energía (artículo 1). El superintendente, como jefe superior, es funcionario de exclusiva confianza del presidente de la República (artículo 4); nombra y remueve al personal de planta de su servicio (artículo 7 letra d); y aunque en su artículo 12 menciona al antiguo Estatuto Administrativo Decreto con Fuerza de Ley 338 de 1960, entendemos se aplica el actualmente vigente (artículo 163 Estatuto Administrativo) (Ley 18.410 de 1985).

Hemos de observar nuevamente que se aplican las disposiciones contenidas en la LOC-BGAE.

\section{Servicios sanitarios}

Según esta norma, es un servicio funcionalmente descentralizado, con personalidad jurídica y patrimonio propio, sujeto a la supervigilancia del presidente de la República a través del Ministerio de Obras Públicas (artículo 1). Su jefe superior es el superintendente (artículo 3); con los límites fijados de planta y dotación máxima de personal, posee la más amplia libertad para establecer su organización interna (artículo 5); en cuanto a su personal, se rige por el artículo 156 (162) del Estatuto Administrativo y es considerada entidad fiscalizadora según los términos del artículo 2 del Decreto Ley 3.551 (artículo 6) (Ley 18.902 de 1990). 
Nuevamente aplica los criterios de la LOC-BGAE, pero agrega la facultad de organizar internamente la entidad, con las restricciones de rigor. Se le aplica el Estatuto Administrativo al personal y se le considera como institución fiscalizadora según el Decreto Ley 3.551.

\section{Salud}

Según esta norma, se le caracteriza como un organismo funcionalmente descentralizado, dotado con personalidad jurídica y patrimonio propios, regido por su ley y reglamento y que se relacionará con el presidente de la República a través del Ministerio de Salud (artículo 106). Está sometida al sistema de Alta Dirección Pública. Su jefatura superior, el superintendente, será designado por el presidente de la República según las normas de la Ley 19.882 (artículo 109). Por su parte, su personal somete a las disposiciones del Estatuto Administrativo, en especial su artículo 162, y se le califica como institución fiscalizadora, según lo dispuesto en el artículo 2 del Decreto Ley 3.551 (artículo 129) (Decreto con Fuerza de Ley 1, de 2006).

Como observamos, se cuadra con el concepto de la LOC-BGAE sobre servicio público descentralizado.

\section{Casinos de juegos}

En este caso, se le caracteriza como organismo autónomo, con personalidad jurídica y patrimonio propio, regido por su ley y reglamentos, y que se relaciona con el presidente a través del Ministerio de Hacienda. Se rige por el sistema de Alta Dirección Pública (artículo 35). El superintendente será funcionario de exclusiva confianza del presidente de la República, y será considerado alto directivo publico según la Ley 19.882. El personal se rige por el Estatuto Administrativo, y es designado y removido por el superintendente de acuerdo a las normas estatutarias, sin perjuicio de las normas especiales (artículos 40 y 42 número 6) (Ley 19.995 de 2005).

Encontramos otro caso de autonomía de jerarquía legal, aunque la descripción es consistente con ser funcionalmente descentralizada. Su jefatura y personal se regula por las normas del Estatuto Administrativo y normas especiales.

\section{Pensiones}

La norma en cuestión la caracteriza como organismo público descentralizado, con personalidad jurídica y patrimonio propio, que se rige por su ley y su estatuto orgánico, relacionándose con el presidente de la República por intermedio del Ministerio del Trabajo y Previsión Social, a través de la Subsecretaría de Previsión Social. La entidad está sometida al sistema de Alta Dirección Pública (artículo 46). Su jefe superior, el superintendente, tiene la potestad de organizar y determinar las funciones con 
sujeción a la dotación máxima y planta de personal establecida (artículo 49). Su personal se rige por lo establecido en el artículo 51, que remite su regulación al sistema vigente en la antigua Superintendencia de AFP, esto es, al artículo 95 del Decreto Ley 3.500, es decir, a través de un estatuto establecido especialmente para dicho efecto, lo que surge en la norma Decreto con Fuerza de Ley 101 de 1980, que señala que a la Superintendencia y su personal no le son aplicables las normas generales o especiales que regulan la Administración del Estado, tanto centralizada como descentralizada, salvo lo dispuesto en el Decreto Ley 1.263 (artículo 16) (Ley 20.255, 2008). ${ }^{6} \mathrm{O}$ sea, se usa la normativa del sector privado.

Nuevamente se utiliza la figura de órgano descentralizado, de acuerdo a la LOC-BGAE.

\section{Medio ambiente}

Esta ley establece, en su artículo segundo el texto que regula a la Superintendencia, que es un servicio público funcionalmente descentralizado, con personalidad jurídica y patrimonio propio, sometido a la supervigilancia del presidente de la República a través del Ministerio del Medio Ambiente. Se le considera entidad fiscalizadora según el Decreto Ley 3.551, está sometido al sistema de la Ley 19.882 y se le aplica el Decreto Ley 1.263 (artículo 1).

Más adelante, el artículo 4 señala que el superintendente será designado por el presidente de la República según lo establecido en la Ley 19.882. El personal se rige por las disposiciones legales y reglamentarias y, supletoriamente, por lo establecido en el Estatuto Administrativo (artículo 8). Más adelante, señala que el superintendente, con las limitaciones de la planta y dotación máxima de personal, establecerá la organización interna de la entidad, y las funciones y denominaciones de las unidades internas (artículo 9) (Ley 20.417 de 2010).

Nuevamente, la figura elegida para las estas entidades es la descentralización funcional, sometiendo al personal de forma indirecta al Estatuto Administrativo y entregando gran amplitud para determinar la organización interna de la entidad.

\section{Educación}

En este caso, se le califica como entidad funcionalmente descentralizada y territorialmente desconcentrada, dotado de personalidad jurídica y patrimonio propio, y que se relaciona con el presidente de la República a través del Ministerio de Educación. Se le considera institución fiscalizadora según el Decreto Ley 3.551 y está afecto al Sistema de Alta Dirección Pública (artículo 47).

6. Su Estatuto Orgánico está en el Decreto con Fuerza de Ley 101 de 1980. 
Más adelante, se establece que el superintendente es un funcionario de exclusiva confianza del presidente de la República (artículo 99); éste puede designar y remover al personal del servicio en conformidad a la ley y las normas estatutarias (artículo 10o, letra d), y el personal está sujeto a las disposiciones del Estatuto Administrativo (artículo 102). El superintendente establecerá con sujeción a la planta de personal, la organización interna, y la denominación y funciones de las unidades internas (artículo 103) (Ley 20.529 de 2011).

Se repite la modalidad ya establecida: servicio público funcionalmente descentralizado, con personal sometido al Estatuto Administrativo y con gran flexibilidad para establecer la organización interna.

\section{Insolvencia y reemprendimiento}

Como última de su especie en ser creada, repite los patrones ya mencionados: entidad funcionalmente descentralizada, con personalidad jurídica y patrimonio propio, relacionado con el presidente de la República a través del Ministerio de Economía, Fomento y Turismo. Se agrega, además, el ser «institución autónoma», calificándosele además como institución fiscalizadora según el Decreto Ley 3.551; y afecto al Sistema de Alta Dirección Pública (artículo 331).

El superintendente es elegido por el presidente de la República a través del Sistema de Alta Dirección Pública (artículo 334); esta autoridad determinará los niveles internos de la entidad y el personal adscrito a ellos (artículo 335); el personal se rige por las disposiciones del Estatuto Administrativo y los fiscalizadores y profesionales se someterán a las disposiciones del artículo 162 de dicha entidad (artículo 336) (Ley 20.720 de 2014).

Repite la configuración que ya hemos visto anteriormente, pero identifica descentralización funcional con ser institución autónoma.

\section{Proyecto de Ley sobre Superintendencia de Telecomunicaciones}

Entre los proyectos de creación de entidades similares, debemos mencionar el referido a la creación de una Superintendencia de Telecomunicaciones (Boletín 8.034-15), que en su artículo 1 la caracteriza como «servicio público funcionalmente descentralizado, dotado de personalidad jurídica y patrimonio propio, sometido a la supervigilancia del presidente de la República a través del Ministerio de Transportes y Telecomunicaciones».

Seguidamente, lo califica como institución fiscalizadora según el Decreto Ley 3.551; afecto al sistema de Alta Dirección Pública, y sometido a las disposiciones del Decreto Ley 1.263 sobre Administración Financiera del Estado.

El superintendente será nombrado por las normas del título 4 de la Ley 19.882, sobre Alta Dirección Pública (artículo 5); podrá nombrar y remover al personal de la 
Superintendencia según las normas legales y estatutarias (artículo 5 letra d); establecerá con sujeción a la planta y dotación máxima de personal su organización interna, las unidades internas con sus denominaciones y funciones (artículo 7). El personal estará sometido a las disposiciones del Estatuto Administrativo, sin perjuicio de las normas contenidas en la ley y los reglamentos especiales (artículo 9) (Boletín 8.034-15 de 2011).

\section{Otras entidades similares}

Fuera del caso de las superintendencias, encontramos entidades también calificadas como fiscalizadoras, pero diferentes a éstas, y que cumplen además funciones de administración activa en diversos ámbitos.

\section{Servicio Nacional de Aduanas}

En este caso debemos recurrir a dos normas: el Decreto con Fuerza de Ley 329, ley orgánica de la entidad que, en el artículo 1, lo caracteriza como dependiente del Ministerio de Hacienda, para después regular su estructura interna. Sin embargo, la clave en este punto la entrega el Decreto con Fuerza de Ley 30, Ordenanza General de Aduanas, que en su artículo 1 describe a esta entidad como:

Servicio público, de administración autónoma, con personalidad jurídica de duración indefinida, y se relacionará con el Poder Ejecutivo a través del Ministerio de Hacienda. Este servicio será denominado para todos los efectos legales como «institución fiscalizadora» y su domicilio será la ciudad de Santiago (Decreto con Fuerza de Ley 329 de 1979) (Decreto con Fuerza de Ley 30 de 2005).

Continuando con su descripción, retomamos el Decreto con Fuerza de Ley 329, señalando que su artículo 4 dispone que su director nacional sea funcionario de exclusiva confianza del presidente de la República. En el número 15 del citado artículo 4 , señala que el director puede dictar resoluciones generales o particulares que fueren necesarias en materia relativas a personal en conformidad al Estatuto Administrativo y demás disposiciones legales vigentes, por lo cual se desprende la aplicación de estas normas a sus funcionarios.

Como vemos, su caracterización se aproxima mucho a un órgano descentralizado, aunque en la primera norma lo califica de «dependiente» y la segunda lo trata de autónomo. Por último, es calificada como institución fiscalizadora, lo que entendemos relacionado con el Decreto Ley 3.551 con un esquema administrativo anterior a la LOC-BGAE. 


\section{Servicio de Impuestos Internos}

Su norma relevante para este análisis es el Decreto con Fuerza de Ley 7 , que en su artículo 2 señala que depende del Ministerio de Hacienda, por lo cual nos encontramos con una entidad centralizada administrativamente. Su director, según el artículo 6, es funcionario de exclusiva confianza del presidente de la República y será seleccionado, nombrado y remunerado según lo contenido en el título 4 de la Ley 19.882. Su personal se rige, según lo establecido en el artículo 21, por lo dispuesto en el Decreto con Fuerza de Ley 338 de 1960, o la norma que lo reemplace, esto es, el actual Estatuto Administrativo (Decreto con Fuerza de Ley 7 de 1980). Como vemos, éste es uno de los pocos casos de una entidad fiscalizadora de tipo centralizado, y su personal se rige por las normas aplicables al sector público.

\section{Fiscalía Nacional Económica}

Establecida en el Decreto Ley 211 de 1973 en su versión actualizada, en su artículo 33 señala:

La Fiscalía Nacional Económica será un servicio público descentralizado, con personalidad jurídica y patrimonio propio, independiente de todo organismo o servicio, sometido a la supervigilancia del presidente de la República, a través del Ministerio de Economía, Fomento y Reconstrucción.

Más adelante, señala que el fiscal nacional económico será nombrado por el presidente de la República a través del procedimiento establecido en el párrafo 3 del título 4 de la Ley 19.882, pudiendo renovarse su nombramiento por una sola vez. Sigue el mismo artículo indicando que su jefe es designado por Alta Dirección Pública y su término en el cargo contempla cuatro causales precisas, dos de las cuales dependen del presidente de la República y deben ser informadas favorablemente por la Corte Suprema a petición del Ministerio de Economía. Observamos una manera más complicada para su remoción, por lo cual escapa al esquema de la descentralización.

El personal del servicio se regirá por el Estatuto Administrativo, según se desprende del artículo 35, y las normas especiales contenidas en el cuerpo legal referido, lo que es congruente con su calidad (Decreto Ley 211 de 1973). El texto es claro, es una entidad descentralizada funcionalmente, pero con un régimen especial para su jefe superior.

\section{Dirección del Trabajo}

Su norma se encuentra en el Decreto con Fuerza de Ley 2 de 1967, y lo describe en su artículo 1 como un «servicio técnico dependiente del Ministerio del Trabajo y Previsión Social, con el cual se vincula a través de la Subsecretaría del Trabajo». El artículo 
2 señala que la entidad estará a cargo de un funcionario denominado director. Por su parte, el artículo 46 señala que los cargos de director y subdirector serán de exclusiva confianza del presidente de la República. Su personal se rige por lo dispuesto en el Estatuto Administrativo, como se desprende de lo establecido en los artículos 5 letra g, y 50 (Decreto con Fuerza de Ley 2 de 1967). Este es otro caso de una entidad centralizada, según el antiguo esquema administrativo común a la época.

\section{Proyecto de ley sobre Servicio Nacional del Consumidor}

Debemos referirnos en este punto al proyecto que se tramita actualmente en el Parlamento sobre nueva institucionalidad y facultades fiscalizadoras para el Servicio Nacional del Consumidor, Sernac (Boletín 9.369-03). En la actualidad, dicha entidad es un:

servicio público funcionalmente descentralizado y desconcentrado territorialmente en todas las regiones del país, con personalidad jurídica y patrimonio propio, sujeto a la supervigilancia del presidente de la República a través del Ministerio de Economía, Fomento y Reconstrucción (artículo 57).

Por su parte, se caracteriza al director nacional como jefe superior del Servicio, quien puede con sujeción a la planta y la dotación máxima del personal, establecer la organización interna y determinar denominaciones y funciones que corresponda a cada una de las unidades del Servicio (artículo 59). Por aplicación de las normas de la LOC-BGAE, entendemos que el director es funcionario de exclusiva confianza del presidente de la República y que al servicio se le aplica las normas del Estatuto Administrativo.

El proyecto en trámite inserta un inciso segundo al artículo 57 y le hace aplicable el Sistema Alta Dirección Pública, lo califica como entidad fiscalizadora según el Decreto Ley 3.551 y le aplica el Decreto Ley 1.263. El nuevo artículo 59 señala del jefe superior del Servicio: «El director nacional será el jefe superior del Servicio», y más adelante detalla su forma de designación por el presidente de la República desde una terna propuesta por el Consejo de la Alta Dirección Pública, con el voto favorable de cuatro quintos de sus miembros. Durará cuatro años en su cargo, pudiendo renovarse sólo una vez en él. En cuanto al término del mandato, la misma norma propuesta detalla cuatro causales, de las cuales dos establecen la remoción por un procedimiento en que participa la Corte Suprema a través de un informe, a solicitud del ministro respectivo y siendo decretada finalmente por el presidente de la República (Boletín 9.369-03 de 2014).

Como se puede observar, el cambio opera en el proyecto sólo sobre la jefatura superior, no cuestionando la naturaleza jurídica del Servicio. Se mantienen las facultades respecto de la planta y dotación máxima. 


\section{Comentarios}

Como observamos, los primeros intentos de regulación de una superintendencia fueron estructurados como una reacción a una Administración del Estado burocrática y centralizada, con una calidad de autonomía de nivel legal, previo a la LOC-BGAE. Con posterioridad, asumen en general la forma de entidad funcionalmente descentralizada, lo cual ha sido la tendencia hasta el último proyecto de ley presentado en la materia. En el caso de los demás servicios, llamados fiscalizadores, pero de administración activa, quedan algunos remanentes con el sistema centralizado, pero la evolución indica claramente su paso a la descentralización funcional.

Algunas entidades mantienen a su jefe superior en su calidad de funcionario de exclusiva confianza del presidente, mientras que otros se han sometido al régimen de la Alta Dirección Pública. Se ha establecido en algunos de ellos un mecanismo, combinando para ciertas causales de cesación en su cargo, esto es, la remoción, limitando la discrecionalidad de la exclusiva confianza. Esto es criticado por Camacho, que señala que afecta la debida autonomía que debería tener una entidad de este tipo, que debería seguir el sistema de agencias o administraciones independientes (Camacho, 2010: 158-159). En algunos casos, todos los funcionarios son de exclusiva confianza del jefe superior, en otros los designa según las normas estatutarias.

En otros pocos, la norma aplicable al personal es de derecho privado, en otros, es de derecho público, teniendo como norma principal el Estatuto Administrativo. En gran parte de ellas, si bien existen límites en cuanto a estructura y máximo de dotación, la autoridad superior establece las unidades con denominación y funciones.

\section{Jefaturas superiores colegiadas}

Otro aspecto a considerar en el tema de las autonomías es la instalación de jefaturas colectivas denominadas «consejos directivos», en lugar de la designación de una autoridad unipersonal. La LOC-BGAE señala que, en circunstancias excepcionales, la ley podrá establecer consejos u órganos colegiados, en la estructura de los servicios públicos con las facultades que le señale, «incluyendo la de dirección superior del servicio» (artículo 31, inciso final).

A nuestro juicio, una decisión de este tipo debe ser sumamente meditada puesto que, aunque tenga buenas pretensiones, puede provocar efectos indeseados, como conducción errática e injerencia de factores externos al técnico que trastornen el correcto desempeño de la entidad. En este caso, sería más prudente establecer autoridades unipersonales con órganos de asesoría.

Un caso donde se estableció y funciona una entidad colegiada superior, lo encontramos en el Consejo para la Transparencia. El artículo 36 señala que la dirección y administración superior de la entidad corresponderá a un consejo directivo, com- 
puesto por cuatro miembros designados por el presidente de la República, previo acuerdo del Senado. Se establece un director ejecutivo de la entidad, claramente subordinado al consejo (artículo 42). Su estructura y funcionamiento, a pesar de las polémicas que normalmente se pueden producir, han sido validados con el tiempo. Lo opuesto ha sucedido, en jerarquía constitucional, con el Consejo Directivo del Servicio Electoral, establecido de acuerdo a la Ley 20.86o. Cuestionamientos a dos de sus consejeros por causas externas y una agria polémica pública entre sus restantes miembros, le han restado legitimidad a una entidad clave en el funcionamiento del sistema democrático.

Fuera de los aspectos contingentes, en el proceso legislativo debe discutirse con mayor profundidad el tema de la conveniencia en crear entidades colegiadas como jefatura superior. En efecto, parece muy pertinente en el caso del Banco Central de Chile, debido a la complejidad de la dirección de la política monetaria, donde es indispensable tener varios expertos abordando los problemas desde diferentes ángulos (artículo 6 de LOC-BCCH).

En el caso de la Contraloría General de la República, es conveniente una jefatura unipersonal, ya que lo que se busca es una dirección fuerte y certeza jurídica (artículo $98 \mathrm{CPR}$, en relación con artículo 2 de LOA-CGR). Sin embargo, no todos piensan del mismo modo: Francisco Zúñiga, ante la propuesta de la colegialidad en instituciones autónomas del Estado, en específico la Contraloría, señala que sería recomendable en las instituciones fiscalizadoras, ya que «en la toma de decisiones asegura un mecanismo de mayor reflexión de las decisiones, evita la arbitrariedad y la politización.?

\section{Casos del INE y el SII}

En el caso del INE y del SII, que abrieron nuestra presentación, estamos también ante servicios públicos de administración activa, o sea, entidades que prestan servicios de atención directa a los administrados.

En el primero, existe un proyecto de ley, Boletín 10.372-03, que crea nueva institucionalidad del Sistema Estadístico Nacional. En su artículo 6, establece el Instituto Nacional de Estadísticas (INE) como

organismo técnico, independiente y descentralizado, encargado de las estadísticas y censos oficiales de la República, que se relacionará con el presidente de la República a través del Ministerio de Economía, Fomento y Turismo y estará afecto al Sistema de Alta Dirección Pública.

7. Mariajosé Soto, «Francisco Zúñiga: «Una Contraloría con órgano colegiado evita la arbitrariedad»», La Tercera, 3 de julio de 2016, disponible en http://bit.ly/2Be7ET5. 
Más adelante, por el artículo 9, crea dentro de INE el denominado «Consejo Estadístico Nacional», órgano colegiado de carácter técnico con amplias atribuciones. Según el artículo 11, se compondrá de cinco miembros elegidos por el presidente de la República con el acuerdo del Senado. Por último, el artículo 16 establece la figura del presidente del Consejo como ejecutor de las políticas dictadas por éste. Más adelante, se establece la figura del director del Instituto Nacional de Estadísticas, quien será elegido según las normas de la Alta Dirección Pública dentro de una lista propuesta por el Consejo de la Alta Dirección Pública, remitida al Consejo Estadístico Nacional para su posterior nombramiento por el presidente de la República (artículo 19).

El proyecto en comento es extenso y con mucha regulación orgánica y normas especiales en la materia. Sólo destacaremos el hecho que crea un Consejo, donde en la elección de sus miembros aparece nuevamente el Senado, lo que puede traer interferencia política indebida. Por otra parte, dicho consejo interviene en un sistema de doble paso para elegir al director del INE y con mucha complicación procedimental. Lo mejor hubiera sido que dicho consejo no participara en la designación del director y se estableciera como órgano consultivo, dentro de la entidad (Boletín 10.372-03 de 2015).

En el segundo caso, Servicio de Impuestos Internos, el proyecto de ley Boletín 9.951-05, presentado por el senador Ossandón, se establece una reforma constitucional que eleva a dicha jerarquía al SII, con lo que crea un consejo directivo de cinco miembros designado de forma mixta: dos por el presidente de la República, uno por el Banco Central, uno por el Senado y otro por la Cámara de Diputados ratificado por el Senado. Uno de sus miembros sería el presidente del Consejo Directivo. Durarían seis años en su cargo, renovados por parcialidades. En su exposición de motivos, e invocando la crisis en las instituciones públicas, propone esta reforma en base a la importancia de sus atribuciones y criticando su dependencia según lo establece el artículo 2 del Decreto con Fuerza de Ley 7/1980, que establece su ley orgánica. Para mejorar su gestión, transparencia y profesionalizarlo propone, como hemos visto, elevarlo a rango constitucional como autónomo y establecer en su jefatura un consejo directivo (Boletín 9.951-05 de 2015).

Personalmente, estimamos que, aunque bien intencionada, la solución es exagerada. En primer lugar, no se garantiza el mejor desempeño de un servicio público con establecerlo en la Constitución, lo cual es una falsa expectativa. En segundo lugar, la carta magna es un texto breve que debe contener las disposiciones más esenciales de la organización de un Estado, y no comenzar a reglamentar servicios públicos. Además, una estructura superior colegiada con un presidente de "Consejo Directivo», en un órgano encargado de la aplicación y fiscalización de los impuestos será contraproducente, pues creará tensiones y problemas en vez de lograr unidad de mando. Por último, su designación, en que participan autoridades políticas, puede contaminar con dichos factores una elección que debería ser eminentemente técnica. Sería mejor 
establecer un consejo asesor del director, con funciones muy delimitadas sin entrabar la labor del jefe superior.

Más recomendable sería establecerlo como un servicio público funcionalmente descentralizado, con normas de integración y carrera funcionaria que resguarden su carácter técnico y profesional.

\section{Conclusión y propuestas de solución}

Del análisis expuesto, podemos llegar a las siguientes conclusiones y propuestas. En cuanto a los ministerios, la solución lógica es agrupar los existentes en sectores afines bajo un solo ministro de Estado y dividirlo en campos o subsectores a través de las subsecretarías respectivas, cada una dotada con las suficientes atribuciones para su labor y coordinadas con el resto del sistema. La creación de diversos ministerios, si bien especializa el tratamiento de los temas, sólo tenderá a fragmentar los esfuerzos en un ámbito más amplio, dislocando la acción del Estado. Si la adecuación se efectúa de buena manera, concentrará en entidades especializadas labores determinadas y, si son debidamente coordinadas con los demás órganos con los que deben colaborar, evitará el crecimiento descontrolado del aparato estatal. Se trata más bien de un reordenamiento y no de la expansión de la Administración Pública. Más Estado no siempre es mejor Estado, pero es mucho mejor que uno prácticamente inexistente o disminuido.

Todo lo expuesto anteriormente implicará una readecuación de las normas relativas a los ministerios y subsecretarías, sugiriéndose una modificación y actualización de las disposiciones contenidas en la LOC-BGAE, con los ajustes en las normas orgánicas respectivas.

Respecto de las superintendencias, la tipología de servicios públicos aplicable es la funcionalmente descentralizada, con personalidad jurídica y patrimonio propio, diferente del fiscal. Si bien pueden existir variaciones debido a cada particular función, estimamos que no debe apartarse de las tipologías establecidas en la LOC-BGAE. Por lo tanto, deberán adecuarse las normas discordantes eliminando la denominación de «autónoma» en sus definiciones, para evitar confusión con las autonomías constitucionales.

Es necesario establecer expresamente el concepto de «institución fiscalizadora» para distinguir a las superintendencias, puramente fiscalizadoras por su específica misión, de las otras entidades que mencionamos que, si bien fiscalizan, son también de administración activa. Esto implicaría establecer categorizaciones dentro de la descentralización funcional, o bien, redefinir sus características, según el tipo de función a seguir.

Finalmente, no conviene permitir el desorden en la organización de Administración Pública, por lo que deben hacerse ajustes en la categorización de los servicios públicos antes que produzca efectos negativos en la marcha del Estado. 
Consecuencia de lo anterior, estimamos que no es recomendable insistir en la fórmula de establecer masivamente autonomías tipo Contraloría o Banco Central, como tampoco recurrir a la consagración constitucional del respectivo órgano público. Dichas propuestas son sólo iniciativas mal enfocadas, que consumirán recursos y tiempo valioso en encontrar una solución que, incluso con dichas reformas aprobadas, se encuentran a nivel legal y no constitucional. Las autonomías constitucionales definidas en el presente texto no son la solución al problema en entidades de administración activa, sino la modernización de la Administración del Estado. Para ello, se necesitará un consenso político del cual no hay visos a la fecha de este escrito. Los casos del Consejo Nacional de Televisión y del Consejo para la Transparencia deben ser seguidos para evaluar su evolución.

En cuanto al jefe superior de los servicios públicos, es necesaria la aplicación y extensión del sistema de Alta Dirección Pública, con el objeto de evitar el criterio discrecional político que incida en la designación de esta autoridad, velando cumplimiento de altas exigencias profesionales y personales. También, es factible establecer un sistema de las causales para terminar el período de un jefe superior, para regular el caso de las remociones y cerrar la idea del funcionario de exclusiva confianza para estas entidades.

En relación al establecimiento de los órganos directivos colegiados, su adopción debe considerar muchos factores y ser producto de un análisis muy cuidadoso, puesto que podría crear un lastre burocrático que aumente las probabilidades de factores político-partidistas en órganos administrativos, junto con el surgimiento de una especie de «nobleza administrativa» dentro de la estructura de los servicios públicos, lo que lo convertiría más en un obstáculo que en una ayuda.

En órganos fiscalizadores, por ejemplo, lo más conveniente es concentrar la cabeza en un solo jefe superior, asesorado con personas idóneas, las que se podría elegir de acuerdo a la Alta Dirección Pública, pero más bien colaboradores y no superiores jerárquicos. En cambio, en los demás órganos de administración podría ser posible la creación de entidades colectivas superiores, pero deberían ser casos muy calificados.

Debe reemplazarse la participación del Senado para la designación de ciertas autoridades, o bien, la intervención de la Corte Suprema para la remoción de algunas de ellas, método utilizado en varias entidades, y se proponen en algunas iniciativas. Este procedimiento sólo debe utilizarse en las más altas autoridades de la nación, ya que en exceso distrae tiempo y recursos que pueden ser utilizados en sus funciones constitucionales. Además, hace descender a estas altas autoridades con frecuencia en asuntos propios de la Administración y, es posible, especialmente en el caso del Senado, de intervención de criterios políticos inconvenientes dentro del aparato público. Es recomendable que el Consejo de la Alta Dirección Pública asuma estas labores en la designación y remoción de las autoridades en los servicios públicos, resguardando la debida independencia e idoneidad de sus miembros. 
Respecto de las superintendencias, la solución toma otro camino mucho más complejo, que sería perfeccionar y extender el sistema de la Alta Dirección Pública haciendo más exigible los requisitos de profesionalización para los diversos cargos a postular. De hecho, esto comenzó con el artículo trigésimo sexto de la Ley 19.882 y se amplió con la Ley 20.955, publicada en el Diario Oficial de 20 de octubre de 2015, que ha efectuado varios ajustes de importancia y extendido las normas de forma paulatina.

Sin embargo, todo esto no puede hacer pensar en una dislocación de la actividad administrativa, la cual debe estar centrada en los procedimientos y la coordinación dentro y fuera de la institución. La tradicional categoría de funcionarios de exclusiva confianza debe ir en franca retirada.

Respecto de la normativa relacionada con el personal, es recomendable hacer aplicable a todas las entidades el Estatuto Administrativo, para evitar la penetración de las normas de derecho privado de forma masiva en el funcionariado estatal. Su uso debe ser excepcional, como lo es hoy. Sin perjuicio de lo anterior, es recomendable efectuar una revisión de las disposiciones del Estatuto, para evitar rigideces innecesarias, sin perder la estabilidad en los cargos. ${ }^{8}$ Los cargos de exclusiva confianza deben quedar para casos muy específicos.

Respecto a la estructura interna de las entidades, parece ser adecuada la fórmula de establecer un marco, con limitaciones como planta y dotación máxima, pero organizándolo el jefe superior según su personal criterio por normativa interna. Puede seguirse el ejemplo de las municipalidades, según la Ley 20.922.

Debe crearse una «Academia de la Administración Pública» para formar, capacitar y perfeccionar a los empleados públicos. La función administrativa comprende a funcionarios distribuidos en el país, con variedad de materias de gran complejidad que deben ser conocidas y actualizadas permanentemente. Ya no basta con la sola instrucción proveniente desde las universidades y entidades afines, como sucedió en el caso del Poder Judicial. ${ }^{9}$

8. En el año 2008, se publicó un artículo sobre los empleados públicos en Chile y su régimen, sugiriendo reemplazar el Estatuto Administrativo por un sistema similar al Código del Trabajo. Pablo Obregón Castro, «Empleados públicos: Chile tiene el Estado más chico de A. Latina, pero uno de los más rígidos», El Mercurio, 13 de mayo de 2008, disponible en http://bit.ly/2DCOvre. Por otra parte, el excontralor Ramiro Mendoza Zúñiga señalaba, después de una breve descripción de la situación: «El tratamiento de la Alta Dirección Pública, con las modificaciones ya hechas, debe ahora dar paso a que abordemos con sinceridad el tratamiento sistémico de la totalidad de los trabajadores de lo público, en el contexto de los nuevos encargos y paradigmas que ahora le hemos impuesto al Estado». Ramiro Mendoza, «Derecho laboral de la función pública: ¿quo vadis?», El Mercurio, 17 de septiembre de 2016, disponible en http:// bit.ly/2BdBuqB.

9. Así encontramos la Academia Diplomática Andrés Bello (1954), la Academia Judicial (1992), la Academia de Capacitación Regional y Municipal (2007), la Academia Parlamentaria (2008) y la creación de 


\section{Referencias}

BECERRA, Katherine (2011). «Las autonomías y sus atribuciones normativas: Caso del Ministerio Público y del Consejo para la Transparencia». En Juan Carlos Ferrada (coordinador), Estudios de derecho público: El principio de la separación de los poderes. Actas de las XL Jornadas de Derecho Público. Santiago: Thomson Reuters.

BoloÑa, Germán (2008). Organización administrativa. Santiago: Legal Publishing.

CAmacho, Gladys (2010). Tratado de derecho administrativo. La actividad sustancial de la Administración del Estado. Tomo 4. Santiago: Legal Publishing.

Celis, Gabriel (2016). Organización administrativa del Estado. Santiago: El Jurista.

Pantoja, Rolando (1998). La organización administrativa del Estado. Santiago: Jurídica.

-. (2010). Tratado de derecho administrativo. Derecho y Administración del Estado. Tomo 1. Santiago: Legal Publishing.

Silva Cimma, Enrique (2008). Estado, gobierno, ciencia política y derecho público. Santiago: Universitaria.

Urrutia, Osvaldo y Pía Weber (2016). «Bases administrativas para un futuro Ministerio del Mar y Borde Costero en Chile». En Juan Carlos Ferrada, Jorge Bermúdez y Osvaldo Urrutia (editores), Doctrina y enseñanza del derecho administrativo chileno: Estudios en homenaje a Pedro Pierry Arrau. Valparaíso: Ediciones Universitarias de Valparaíso.

Vergara, Manuel (2010). Bases para una codificación administrativa. Edición privada. Valparaíso: Imprenta Arte y Gráfica.

\section{Sobre el autor}

Manuel Patricio Vergara Rojas es abogado. Licenciado en Ciencias Jurídicas de la Universidad de Valparaíso. Es ayudante de la Cátedra de Derecho Político de la Universidad de Las Américas, sede Viña del Mar, Chile. Su correo electrónico es mvergararojas@gmail.com.

parte de la Contraloría General de la República del Centro de Estudios de la Administración del Estado, que tiene entre uno de sus objetivos la «formación y capacitación de los funcionarios y servidores públicos en materias transversales y técnicas, para lograr una mejora continua en la gestión pública». Véase «Quiénes somos», Centro de Estudios de la Administración del Estado, disponible en http://bit. ly/2BekgJB. 
La Revista de Derecho Público es publicada, desde 1963, dos veces al año por el Departamento de Derecho Público de la Facultad de Derecho de la Universidad de Chile. Su propósito es la difusión de los avances del derecho público nacional e internacional y la socialización de artículos de investigación inéditos tanto de la comunidad académicas nacional e internacional.

DIRECTORA

Ana María García Barzelatto

SECRETARIO DE REDACCIÓN

Felipe Peroti Díaz

(fperoti@derecho.uchile.cl)

SITIO WEB

revistaderechopublico.uchile.cl

CORREO ELECTRÓNICO

publico@derecho.uchile.cl

LICENCIA DE ESTE ARTÍCULO

Creative Commons Atribución Compartir Igual 4.0 Internacional

La edición de textos, el diseño editorial

y la conversión a formatos electrónicos de este artículo

estuvieron a cargo de Tipográfica

(www.tipografica.cl). 